\title{
REVIEW
}

\section{Transcatheter Pulmonary Valve Replacement}

\author{
Hani Ghawi • Damien Kenny • Ziyad M. Hijazi
}

To view enhanced content go to www.cardiologytherapy-open.com

Received: August 10, 2012 / Published online: October 16, 2012

(C) The Author(s) 2012. This article is published with open access at Springerlink.com

\begin{abstract}
Transcatheter pulmonary valve replacement (tPVR) has evolved into a viable alternative to surgical conduit or bioprosthetic valve replacement. This procedure has paved the way for a more advanced approach to congenital and structural interventional cardiology. Although many successes have been noted, there are still a number of challenges with this procedure, including large delivery systems, the need for a conduit or a bioprosthetic valve as a landing zone for the valve, optimal timing of the procedure to
\end{abstract}

For the Melody valve: ClinicalTrials.gov Identifier: NCT00740870.

For the SAPIEN valve: ClinicalTrials.gov Identifier: NCT00676689.

H. Ghawi · D. Kenny · Z. M. Hijazi ( $ه)$ Rush Center for Congenital and Structural Heart Disease, Rush University Medical Center, 1653 West Congress Parkway, Jones 770, Chicago, IL 60612, USA e-mail: zhijazi@rush.edu

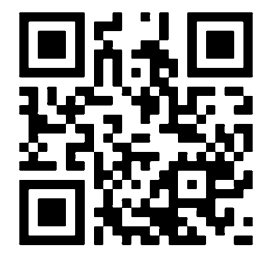

Enhanced content for this article is available on the journal web site: www.cardiologytherapy-open.com prevent right ventricular failure, arrhythmias, and possible death. Research is ongoing to broaden the use of this technology when treating patients with dilated right ventricular outflow tracts, and early experience with a selfexpanding valve model has been reported. Affordability is an important factor that must be considered especially in developing nations. The aim of this review is to emphasize the advancement of tPVR, the benefits and challenges of valve implantation, the current state, and the future innovations associated with this approach.

Keywords: Cardiology; Pulmonic regurgitation; Right ventricular failure; Transcatheter pulmonary valve replacement

\section{INTRODUCTION}

Implantation of a right ventricle (RV) to pulmonary artery conduit has been vital in treating patients with right ventricular outflow tract (RVOT) obstruction with or without pulmonary regurgitation $[1,2]$. Utilizing these conduits has provided positive results in the treatment of uncommon forms of congenital 
heart disease (CHD), such as truncus arteriosus, which were previously considered to be untreatable [3]. Surgical correction utilizing conduits in early life may also be required in patients with pulmonary atresia with ventricular septal defect or transposition of the great arteries with a ventricular septal defect and pulmonic stenosis.

Unfortunately, due to calcification or scar formation leading to valve dysfunction, conduits have limited durability, and progressive conduit dysfunction may lead to pulmonic regurgitation and/or stenosis $[4,5]$. It is estimated that conduit replacement surgery is necessary anywhere between 10-15 years after implantation [6]. More recent data categorize the freedom from reintervention depending on the age of the patient. Batlivala et al. [7] reported freedom from RVOT reintervention to be $90 \% \pm 3 \%$ at 5 years, $67 \% \pm 5 \%$ at 10 years, and $47 \% \pm 8 \%$ at 15 years, respectively.

In an effort to avoid reoperation, balloon dilatation and stent placement has been reported as a palliative treatment option for conduit obstruction [8, 9], although these procedures may result in free pulmonic regurgitation (PR). Free PR progressively leads to $\mathrm{RV}$ dilation that subsequently increases the risk of ventricular arrhythmias, RV dysfunction, and ultimately cardiac death $[8,9]$.

Transcatheter pulmonary valve replacement (tPVR) has advanced into a feasible, less invasive alternative to surgical conduit replacement. Although data evaluating and comparing the function and durability of tPVR with surgical implants are lacking, short-to-medium term outcomes for tPVR are very promising with low morbidity and low valve failure rates $[7,10]$. The focus of this review is to detail the progress and innovations of tPVR, and to display future advancements that accompany this technology.

\section{HISTORY}

In 2000, Bonhoeffer et al. [11] introduced and reported the concept of tPVR mounted on a balloon expandable stent in an ovine model. In his first report, the native biological valves were collected from fresh bovine jugular veins and then trimmed to reduce the size of the delivery system, at the same time maintaining safe attachment of the tissue to the platinum iridium stent. The stent was then expanded to a radial diameter of $18 \mathrm{~mm}$, and the length of jugular vein was sutured to the interior of the stent, spanning the entire axial length of the stent. Device insertion was attempted via the internal jugular approach in 11 lambs. Seven out of 11 devices were successfully implanted; five of the seven valves had the desired location for valve implantation. The stent-valves were explanted 2 months after implantation. Four of the valves were mobile and competent with slight stenosis secondary to visible calcification in the fifth one. Although the overall success rate was low at about 36\%, these attempts provided the platform for human studies [11].

Soon after, the same group reported the first human transcatheter implantation in the pulmonary position [12]. The valve was implanted in a 12-year-old male patient with pulmonary atresia and ventricular septal defect, who had significant stenosis and insufficiency of his $18 \mathrm{~mm}$ Carpentier-Edwards valve conduit that was placed at age 4 years from the RV to the pulmonary artery. The bovine jugular valve was placed via the transfemoral approach and successfully implanted into the degenerated valve of the conduit. The pre-existing pulmonary insufficiency was almost eliminated with subsequent reduction in right ventricular dimensions.

Two years later, Bonhoeffer et al. [13] published further clinical experience in eight 
patients. All patients had successful implantation of the valve in the desired position, and all had significant improvement in their pulmonary insufficiency. Valvar competence was achieved in six patients, whereas relief of conduit obstruction was partial in three patients and this persisted at follow-up. Stent fractures were reported in two patients [13].

\section{CURRENT LITERATURE}

After these initial successful attempts, efforts focused on assessing the effectiveness and safety of these valves as well as their longevity. Bonhoeffer's valve design was eventually acquired by Medtronic and renamed the Melody ${ }^{\circledR}$ Valve (Medtronic Inc., Minneapolis, MN, USA) and implantation was evaluated in further clinical reports [13]. The conclusions from these reports were that (a) the procedure is safe, (b) the procedure is effective in eliminating $\mathrm{PR}$ and reducing the indexed right ventricular volumes, and (c) there is an improvement in the New York Heart Association (NYHA) functional class during a mean follow-up of 10 months [14]. Freedom from surgical explantation was $83 \%$ at 12 months follow up with no mortality reported [14]. Following further clinical experience of tPVR using the Melody valve, Lurz et al. [15] reported the freedom from transcatheter reintervention as follows: 95\%, $87 \%, 73 \%$, and $73 \%$ at $10,30,50$, and 70 months, respectively. It was also noted that patients with a residual gradient $>25 \mathrm{mmHg}$ were associated with a higher risk of reintervention. Recently, a multicenter US clinical trial showed freedom from Melody valve dysfunction or reintervention was almost $95.4 \%$ at 1-year follow-up with a high rate of procedural success (124/136), and improvement in NYHA functional class [16].
The Edwards SAPIEN transcatheter heart valve (THV; Edwards Life sciences LLC, Irvine, CA, USA) was initially introduced as a transcatheter alternative to surgical aortic valve replacement in elderly patients with severe aortic stenosis [17]. An initial report outlined successful deployment in the pulmonary position in 2006 [18]. A subsequent clinical trial demonstrated effective reduction in RVOT gradients, improved clinical symptoms, and sustained pulmonary valve competence at 6-month follow-up (the COMPASSION trial) [19].

\section{CURRENT AND FUTURE TRANSCATHETER VALVES}

There are currently two valves available commercially, as shown in Fig. 1 and described in Table 1. The Melody valve was approved by the US Food and Drug Administration (FDA) in January, 2010 for percutaneous valve replacement under the Humanitarian Device Exemption (HDE) program [20]. The Melody valve is made from a bovine jugular vein valve that is sewn into a platinum iridium stent and preserved in a proprietary sterilant of glutaraldehyde and alcohol $[9,10]$. The Melody valve comes in one size $(18 \mathrm{~mm}$ diameter; length, $28 \mathrm{~mm}$ ) that is crimped to $6 \mathrm{~mm}$ and re-expanded up to $22 \mathrm{~mm}$. Its leaflets are very compliant and flexible.

The Medtronic Ensemble ${ }^{\circledR}$ delivery system (Medronic Inc., Minneapolis, MN, USA), comprises a delivery sheath with a balloon in balloon (BiB) catheter (NuMED Inc., Hopkinton, NY, USA) onto which the valve is front-loaded and crimped. The polytetrafluoroethylene (PTFE) sheath, which covers the valve during delivery is withdrawn just prior to deployment. Three sizes of the outer balloon are available: 18, 20, and $22 \mathrm{~mm}$. 

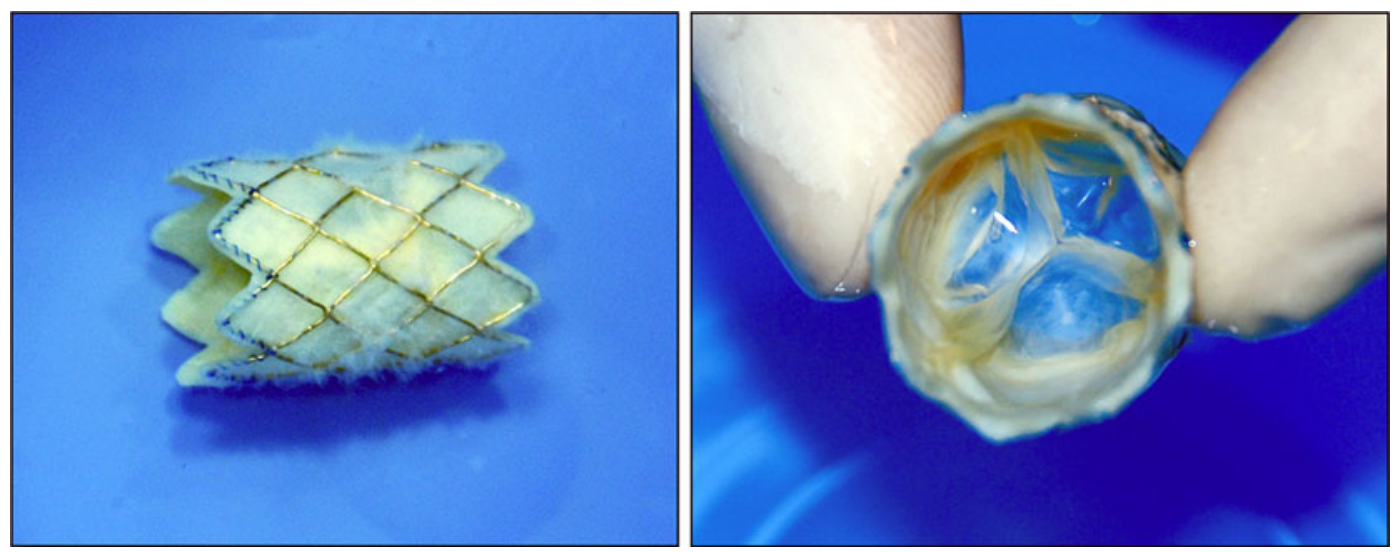

Fig. 1 The Medtronic Melody ${ }^{\circledR}$ pulmonic valve; long axis (left) and short axis views (right)

Table 1 Comparison of Melody ${ }^{\circledR}$ and the SAPIEN ${ }^{\mathrm{TM}}$ valves

\begin{tabular}{lll}
\hline Characteristic & Melody $^{\circledR}$ valve & SAPIEN $^{\text {TM }}$ valve \\
\hline Stent material & Iridium 10\%, platinum $90 \%$ & Stainless steel \\
Valve material & Bovine jugular vein & Bovine pericardium treated with Thermafix \\
Available diameter $(\mathrm{mm})$ & $18-22$ & 23 or 26 \\
Stent height $(\mathrm{mm})$ & 34 & 14.5 or 16 \\
Delivery sheath size $(\mathrm{F})$ & 22 & 22 or 24 \\
\hline
\end{tabular}

The SAPIEN THV, approved for inoperable patients with severe aortic stenosis [21] (not FDA approved for the pulmonic position), is also a bovine valve but produced from three equalsized bovine pericardial leaflets that are handsewn to a stainless steel balloon-expandable stent as shown in Fig. 2 and described in Table 1. There is a fabric cuff covering the lower portion of the stent's frame (ventricular side), which enables a seal with the calcified conduit, may prevent paravalvular leak, and limits stent expansion. The leaflet materials were designed to reduce leaflet stress and maximize coaptation. The valve is preserved in low concentration solutions of buffered glutaraldehyde, and is processed with the Edwards Thermafix ${ }^{\mathrm{TM}}$ (Edwards Life Sciences, Irvine, CA, USA) anticalcification pretreatment that is also utilized in the Carpentier-Edwards PERIMOUNT Magna ${ }^{\mathrm{TM}}$ (Edwards Lifesciences), surgical valve. This process involves heat treatment of the tissue in glutaraldehyde and uses ethanol and polysorbate- 80 .

The valve is available in two sizes: $23 \mathrm{~mm}$ with a stent height of $14.3 \mathrm{~mm}$ and $26 \mathrm{~mm}$ with a stent height of $16 \mathrm{~mm}$ [22]. The valve is mounted on a custom-made 30-mm long balloon. The Retroflex 3 delivery system (Edwards Lifesciences) consists of a balloon catheter and a deflectable guiding catheter, and requires a $22 \mathrm{~F}$ (for the $23 \mathrm{~mm}$ valve) and a $24 \mathrm{~F}$ (for the $26 \mathrm{~mm}$ valve) hydrophilic $35-\mathrm{cm}$ long sheaths. A specialized Edwards Crimper is used to symmetrically crimp the valve onto the balloon. The Placement of AoRTic traNscathetER valves (PARTNER II) trial is currently evaluating the next generation of the 

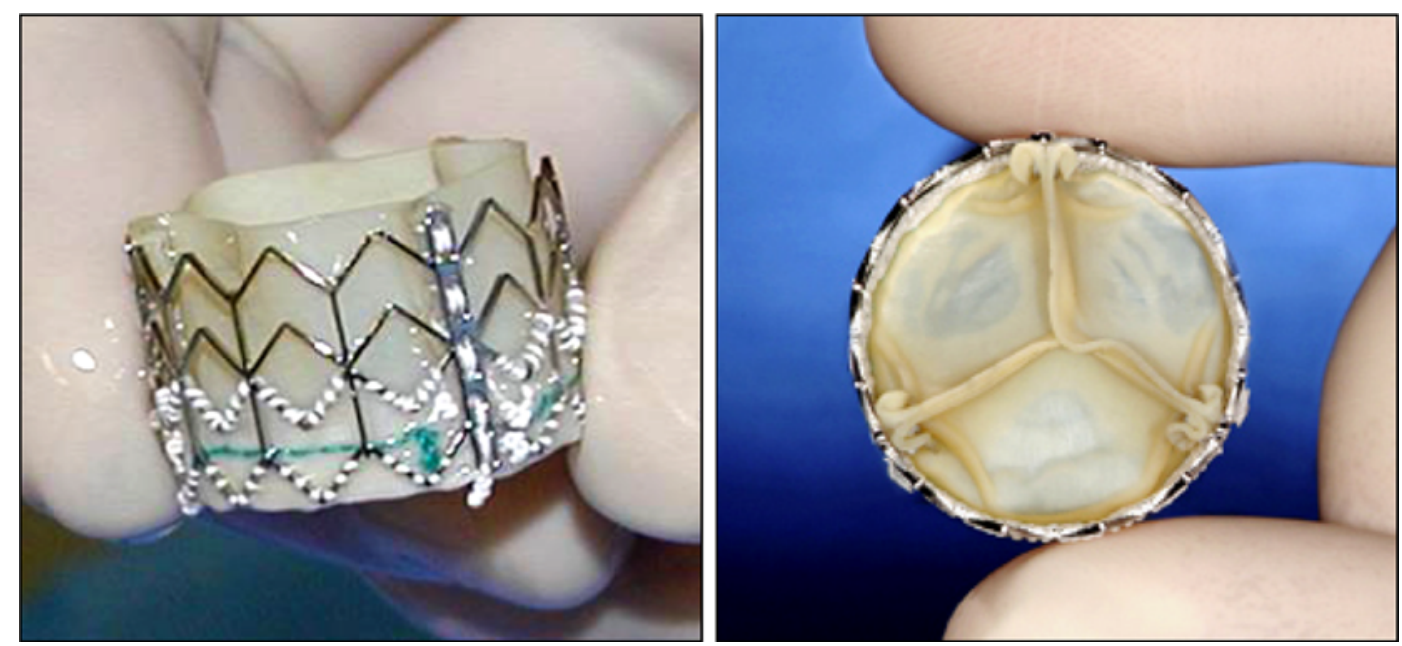

Fig. 2 The Edwards Lifesciences SAPIEN ${ }^{\mathrm{TM}}$ valve; long axis (left) and short axis views (right)

SAPIEN $^{\mathrm{TM}}$ THV, the SAPIEN $\mathrm{XT}^{\mathrm{TM}}$ in the aortic position [23]. The stent material has changed from stainless steel to a cobalt chromium alloy, which allows a smaller delivery profile and sheath size. Currently, the valve is available in Europe, and is also available in a diameter of $29 \mathrm{~mm}$, with a stent height of $19.1 \mathrm{~mm}$. The delivery system, Novoflex catheter (Edwards Lifesciences) is unique because it decreases the required sheath size secondary to its capability to load the valve onto the balloon inside the body. There are no available data for this valve in the pulmonary position. To the authors' knowledge, this valve was implanted in only one patient with a good result (personal communication, Edwards Lifesciences).

Each valve has its own advantages; although the SAPIEN THVs are available in larger sizes and shorter heights, which may be appropriate for larger conduits and challenging anatomy, it has a larger delivery system than the Melody valve, which may render it more difficult to deliver. Interestingly, the SAPIEN ${ }^{\mathrm{TM}}$ THV system does not use a covering sheath; therefore, once it exits its delivery sheath (35-cm long) it may be difficult to retract inside the sheath. Conversely, the Melody system is less bulky, and its retractable sheath protects the valve until it is deployed; however, its limitation to $22 \mathrm{~mm}$ makes it less valuable for those with larger conduits. Deployment of the Melody valve on a $24 \mathrm{~mm}$ balloon has been performed successfully with minimal regurgitation (personal communication, John P. Cheatham, MD).

In a recent study conducted in the authors' center, both valves demonstrated comparable function at short-term follow-up with a greater initial residual RVOT gradient in the SAPIEN cohort; however, this was thought to be secondary to a less aggressive prestenting strategy with the Edwards cohort [24].

\section{INDICATIONS}

The adverse impact of RV dilatation and dysfunction is well studied in patients with tetralogy of Fallot. Exercise intolerance, heart failure, arrhythmias, right ventricular dysfunction, and death, are late complications after repair. The pressure gradient across previously placed surgical conduits increases the pressure and volume load of the RV and may eventually lead to these complications. Numerous studies have attempted to stratify the 
risks; QRS duration of $>180 \mathrm{~ms}$ has been shown to be an independent predictor of sudden death [9]. In 2007, Oosterhof et al. showed early intervention is beneficial in patients with preoperative QRS $>150 \mathrm{~ms}$ [25]. Cardiac magnetic resonance (CMR) imaging has been used to determine the timing of intervention based on RV ejection fraction, volume, and pulmonary regurgitation. Currently, surgical intervention is indicated with indexed right ventricular end-diastolic volumes (RVEDV) $>150 \mathrm{~mL} / \mathrm{m}^{2}$ based on recently published data, as studies have suggested an indexed RVEDV that exceeds $150 \mathrm{~mL} / \mathrm{m}^{2}$ may lead to irreversible $\mathrm{RV}$ dilation despite successful valve replacement [26].

The 2010 American Heart Association statement on the Indications for Cardiac Catheterization and Intervention in Pediatric Cardiac Disease was expanded to include a class 2a indication for tPVR [27]; the recommendation was: 'It is reasonable to consider percutaneous pulmonary valve replacement in a patient with an RV-to-pulmonary artery conduit with associated moderate to severe pulmonary regurgitation or stenosis provided the patient meets inclusion/exclusion criteria for the available valve (level of evidence: B).' These recommendations are somewhat vague, and therefore, to date, indications have mirrored those for published clinical trials [27]. The inclusion and exclusion criteria for both the Melody and SAPIEN valve trials are summarized in Table 2.

\section{PROCEDURAL TECHNIQUE}

After a complete history, physical examination, and reviewing the preprocedural laboratory and imaging investigations, including echocardiography and computed tomography
(CT)/CMR, the patient is taken to the catheterization laboratory. The procedure is performed under general endotracheal anesthesia. Access is usually obtained via the femoral vein (preferred site for valve delivery); however, the procedure may also be performed via the internal jugular vein. A $7 \mathrm{~F}$ and a $5 \mathrm{~F}$ sheath are used for venous and arterial access, respectively. After obtaining access, the patient is given intravenous heparin, to achieve an activated clotting time (ACT) of $>200 \mathrm{~s}$, preferably $>250$ s.

Standard right heart catheterization is performed to assess the preprocedural saturations, pressures, and the pressure gradient across the dysfunctional conduit (Fig. 3a). Angiography is then performed as follows: straight lateral and frontal with $20^{\circ}$ cranial. Selective coronary angiography is performed simultaneously with a noncompliant angioplasty balloon in the RVOT conduit. Adequate angiographic distance (at least $10 \mathrm{~mm}$ ) from the edge of the inflated balloon to the origin of the left coronary artery must exist to place the valve safely without compression of the coronary arteries (Fig. 3b). Angiographic assessment of the RVOT size, anatomy, and RV function is of paramount importance to ensure appropriate valve delivery is feasible (Fig. 3a-d).

It is important to measure the RVOT in two dimensions (utilizing biplane fluoroscopy) to ensure the RVOT is suitable for valve delivery. In the COMPASSION trial, implantation of the $23 \mathrm{~mm}$ valve was recommended when the final conduit (with a bare stent) diameter was between $19-21 \mathrm{~mm}$ and the $26 \mathrm{~mm}$ valve was best implanted when the final conduit diameter was $21-23 \mathrm{~mm}$.

Due to the short height of the Edwards valve and to provide an adequate landing zone, prestenting of the RVOT with a bare metal stent prior to valve delivery is a must and 


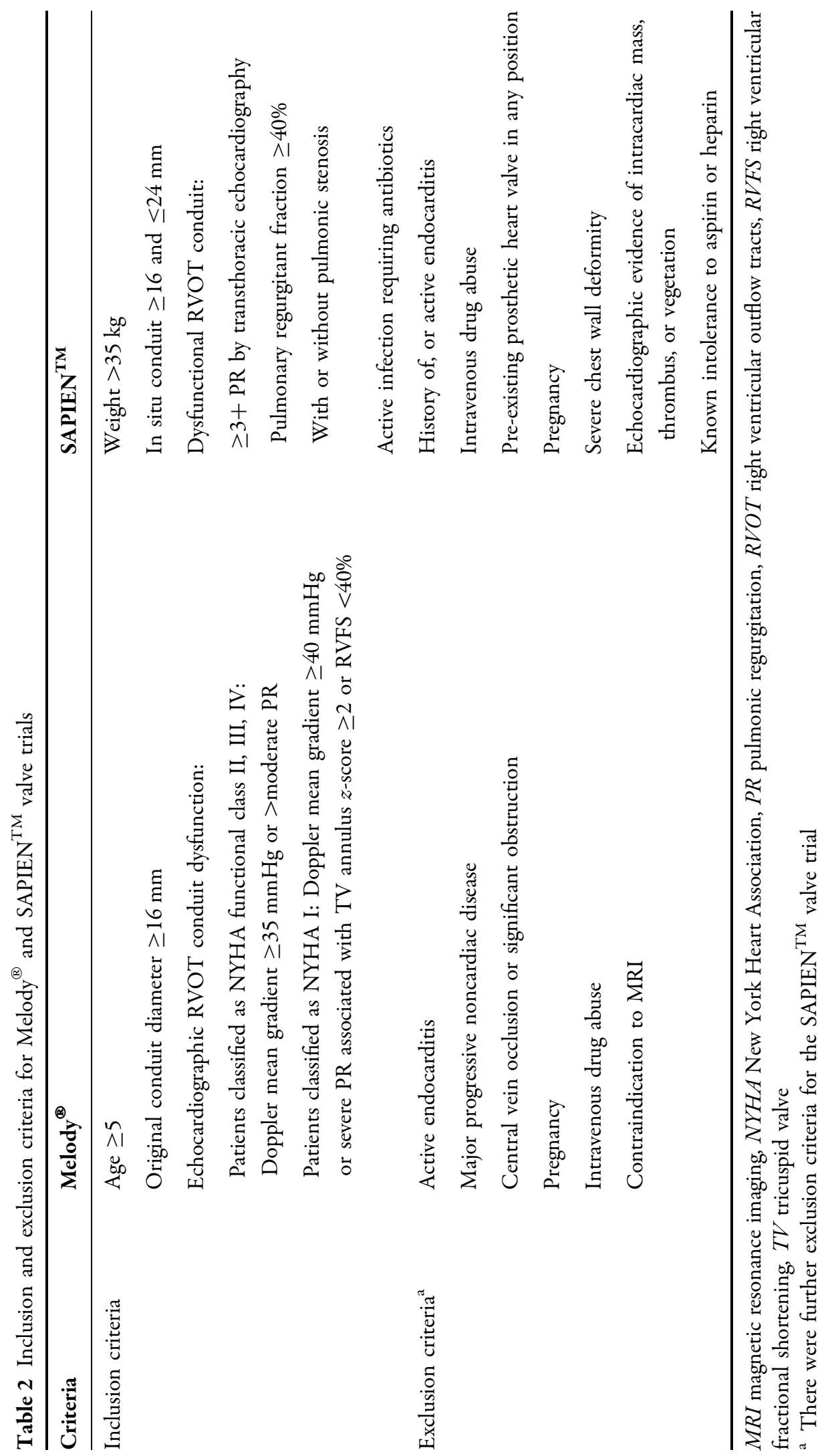



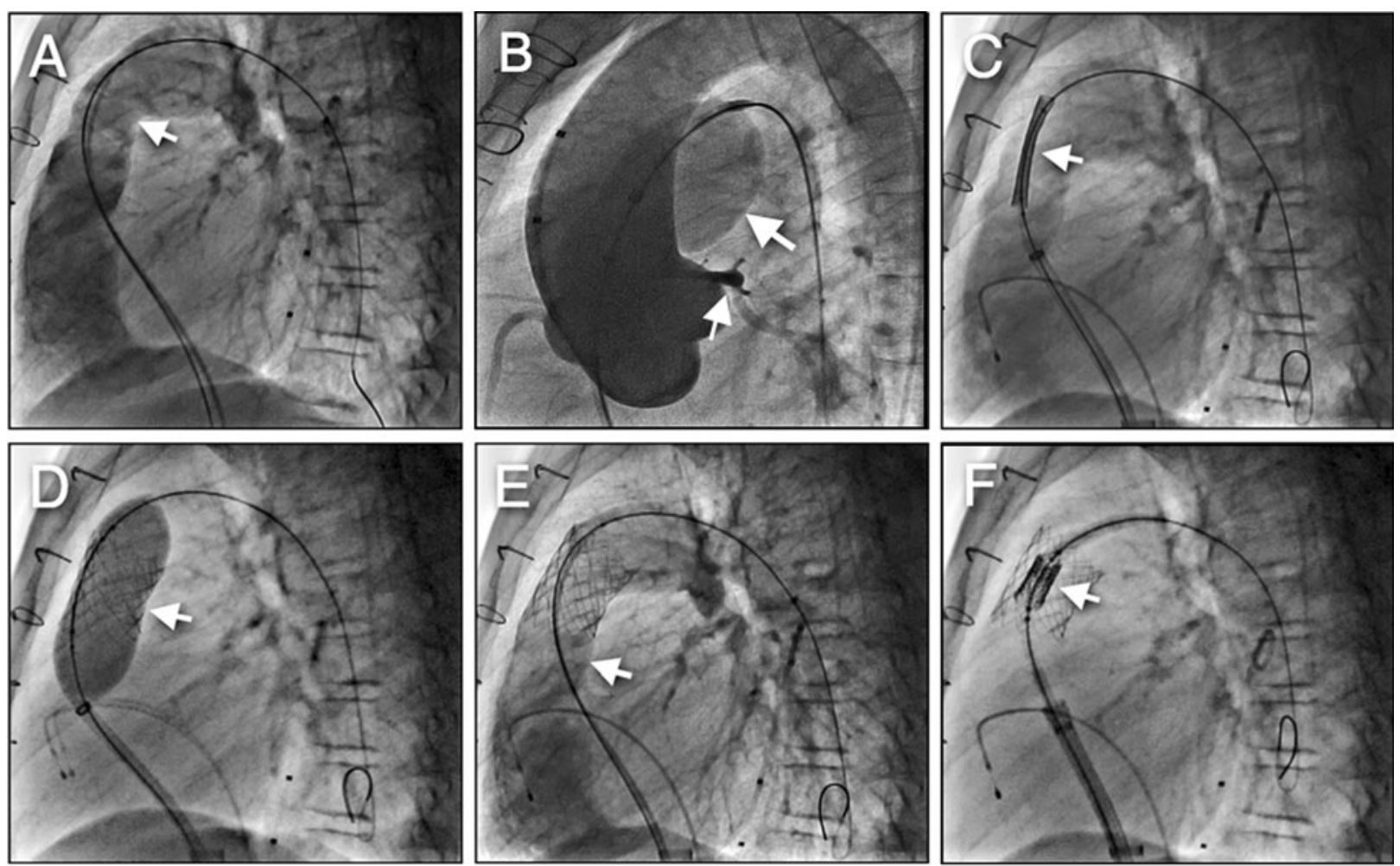

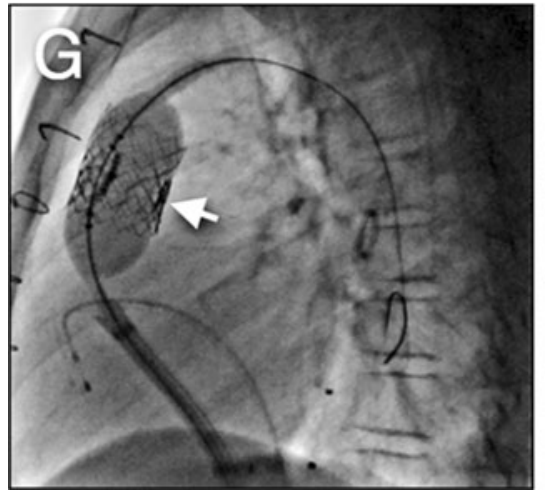

Fig. 3 SAPIEN $^{\mathrm{TM}}$ valve placement steps. a MPA (homograft) angiography demonstrates severe pulmonic regurgitation. b MPA balloon sizing with simultaneous aortic root angiography; large arrow shows the balloon inflation in the RVOT, small arrow demonstrates LCA with an acceptable distance from the RVOT. c Bare-metal stent placement in homograft with hand injection angiography to delineate stent position. d Balloon stent deployment.

prestenting has also become standard (to reduce stent fracture) when implanting the Melody valve (Fig. 3c).

The bare metal stent is usually deployed on a BiB catheter (NuMED Inc; Fig. 3d, e) over a stiff guide wire placed preferably in the left pulmonary artery. Prior to valve insertion, the valve stent is crimped symmetrically using a specialized crimping device onto a $30 \mathrm{~mm}$-long presized balloon catheter. The valve is delivered 

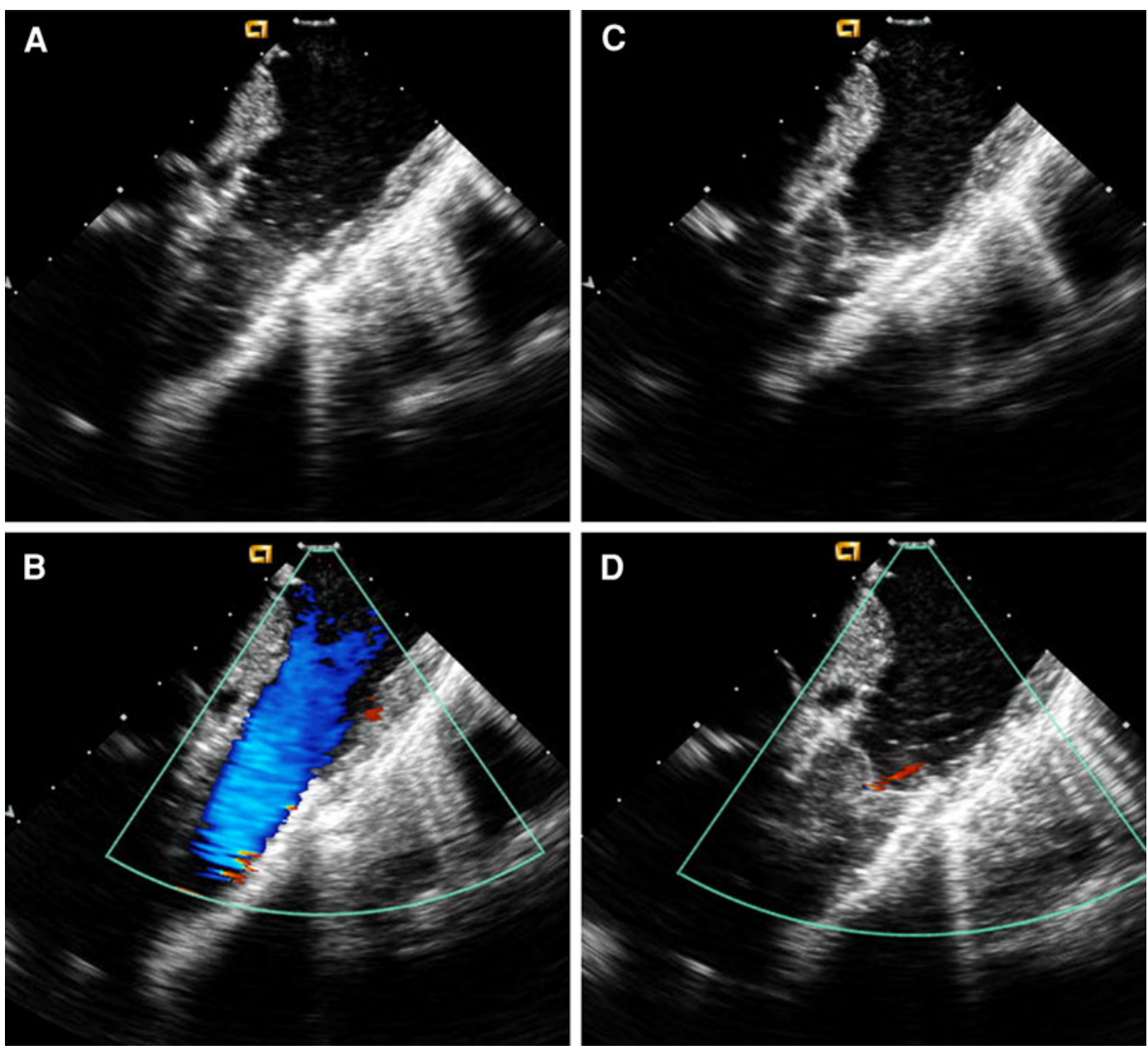

Fig. 4 Intracardiac echocardiography (ICE) images. a Two-dimensional ICE in systole demonstrating complete opening of SAPIEN valve leaflets. b Color Doppler in systole demonstrating no narrowing passing SAPIEN valve.

across the prestented outflow tract over a very stiff guide wire; Meier wire (Boston Scientific Corporation, Natick, MA, USA), or Lunderquist wire (Cook Medical, Bloomington, IN, USA). Multiple angiograms are performed prior to balloon inflation to ensure proper position of the stent; this is usually not necessary if there is a stent already in place (Fig. 3f-i).

Postprocedural imaging with angiography and/or intracardiac echocardiography (ICE) is performed to evaluate the site and function of the implanted valve (Fig. 4). ICE enables

c Two-dimensional ICE in diastole demonstrates complete valve closure. d Color Doppler in diastole demonstrates trivial PR

evaluation of the pressure gradient by Doppler and the degree of valve regurgitation or perivalvular leak.

Hemostasis is achieved after the procedure with either Perclose sutures (Abbott Vascular, Abbott Park, IL, USA) [19], which should have been inserted prior to inserting the large sheath (preclose), or simply by (Figure-of-Eight) suturing technique [28].

Following the procedure, the patient is admitted to the intensive care unit for close observation overnight. Complete physical 
examination, electrocardiogram (ECG), chest $\mathrm{x}$-ray, and echocardiography are performed prior to patient discharge. Aspirin $81 \mathrm{mg}$ is advised for at least 1 year.

Follow-up outpatient visits are recommended at 1,6 , and 12 months, and yearly thereafter. A chest radiograph is obtained at 6 months to investigate the position of the valve/stent and any potential stent fracture. Echocardiography is routinely used to evaluate RV function, regurgitation, and/or stenosis with each visit. CT or CMR is also part of the follow-up protocol.

\section{POTENTIAL COMPLICATIONS}

Procedural complications may necessitate conversion to surgery; these include valve migration, homograft rupture, guide wire injury to a distal branch pulmonary artery, damage to the tricuspid valve, and arrhythmia. Initial reports associated with these complications were documented to be as high as $12 \%$ in early studies [14]; however, recent studies have demonstrated a reduction in major complications to 5-6\% [7]. A study published by Bonhoeffer's group in 2008 reported that after their first 50 patients, procedural complications decreased from $6.0 \%$ to $2.9 \%$ [15].

A recent study demonstrated that $4.4 \%$ of the US cohort possessed unsuitable anatomy for valve implantation due to concerns regarding potential coronary artery compression [7]. This issue may be evident by using CT/magnetic resonance angiography, which may indicate the distance between the coronary artery and conduit; however, this should not be relied upon as stent implantation will distort the pre-existing anatomy, and selective coronary angiography with a noncompliant balloon inflated in the RVOT should always be performed prior to attempted stent/valve implantation.
Conduit rupture has also been reported [15]. Risk factors have yet to be fully elucidated. Increasingly covered stents are being used with aggressive prestenting of heavily calcified conduits. In the event of conduit rupture, selfexpanding covered stents or, if available, balloon expandable covered stents should be used to create a seal and prevent further risk of bleeding [29].

Device-related complications are usually detected postprocedure. The "Hammock" effect-in which the valve does not oppose the stent leading to stenosis-was detected in patients undergoing early Melody valve implantation and was associated with a high incidence of in-stent stenosis [30]. This is attributed to the malapposition of the valve to the stent. The detection of this problem lead to the modification of the design of the Melody valve, in which additional sutures were implanted at all strut intersections. Another problem that can require reintervention is stent fracture, which has been reported to be as high as $43 \%$ without bare-metal stenting of the RVOT [31]. Nordmeyer et al. [32] reported a 75\% freedom from Melody stent fracture (MSF) at 2 years in the native RVOT. In the multicenter trial for Melody valve implantation [16], short and medium-term follow-up data demonstrated that the freedom from stent fracture was $83.7 \% \pm 3.7 \%$ at 7.5 months and $77.8 \% \pm 4.3 \%$ at 14 months. Reduction in the rate of stent fracture has been noted with prestenting of the RVOT [33]. The risk factors for stent fracture were not evaluated in this cohort. Stent fracture has not been reported with the SAPIEN valve.

In December 2011, McElhinney et al. [34] reported the multicenter trial for Melody valve implantation. They assessed, in detail, the risk factors for MSF, valve dysfunction, and reintervention. The median follow up was 30 months. MSF was classified into three types 
according to Nordmeyer et al. [32]: type 1, fracture of one or more strut without loss of stent integrity; type 2, fracture with loss of stent integrity; and type 3, fracture associated with separation of fragments or embolization. Thirtynine out of 150 patients were diagnosed with MSF; 33 patients were classified as type I. Seventeen patients were diagnosed with a type 2 MSF; (11 patients progressed from type 1-2 and six were diagnosed as type 2). One patient had a type III MSF with embolization to the RV of a single strut segment.

Freedom from a diagnosis of MSF was $77 \% \pm$ $4 \%$ at 14 months, $68 \% \pm 5 \%$ at 27 months, and $60 \% \pm 9 \%$ at 39 months, respectively. Freedom from a diagnosis of type II MSF was $85 \% \pm 4 \%$ at 27 months and $74 \% \pm 11 \%$ at 39 months. The authors also assessed the risk factors associated with MSF [34]; severe conduit obstruction and the position of the implanted valve behind the sternum were associated with shorter freedom from MSF.

Valve-in-valve tPVR has been performed to treat the Hammock effect, stent fractures, and residual stenosis. It has been noted that repeat tPVR has resulted in freedom from surgical reintervention [35]. In a multicenter trial for valve-in-valve implantation for failed bioprosthetic heart valves, six patients underwent successful implantation of the Edward SAPIEN valve in the pulmonary position; there was no mortality within the 6 month follow-up period. [36]. However, repeat tPVR is not suitable in all instances. Although, where appropriate, this approach should be considered an alternative to surgery as using this management strategy may indefinitely halt the need for surgical reintervention.

Prestenting has primarily focused on reduction of stent fracture and a recent report with high patient proportion of prestenting (95\%) demonstrated stent fractures as low as 5\%
[33]. Operators have adapted the prestenting technique with covered stents-if these are available-to prevent conduit rupture [35], while others have advocated preparation of a covered stent as a bail out in the case of conduit disruption.

The size of the patient and of the RVOT have limited the available $22 \mathrm{~F}$ delivery system for both the Melody and SAPIEN valves to transfemoral approaches in children over $20 \mathrm{~kg}$. This will limit the extended application of the currently available valves; however, the internal jugular vein may be used in these smaller patients. An alternative approach was also reported for both valves with valve delivery directly through the heart through a sheath placed in the RV free wall $[36,37]$.

Endocarditis has been reported in $3.2 \%$ of patients over a median follow-up of 5 months following implantation of tPVR, [15]. The culprit organisms were Staphylococcus aureus, Streptococcus spp., and also Candida albicans in one patient with compromised immunity [15]. American Heart Association (AHA) guidelines recommendation stated: prophylaxis is reasonable within 6 months after the procedure [38].

\section{CONCLUSION AND FUTURE DIRECTIONS}

Description of transcatheter pulmonary valve implantation in a dysfunctional RV-pulmonary artery conduit over a decade ago is still considered as an important step towards further potential for this emerging field in interventional cardiology. The rapid advancement of this technique and valve design offers patients the opportunity of less invasive intervention/ reintervention and may lead to less morbidity and faster recovery. With an improvement in the 
inevitable learning curve, the rate of procedural complications is dropping significantly [15]. Multicenter trials and development of protocols may broaden the applicability of this technology significantly.

Comparative data with the surgical alternative requires further research. One of the difficulties that interventionists are facing is the size of the delivery system that renders tPVR rather challenging for small children. Therefore, miniaturization of the delivery system/valve should be explored to benefit the thousands of small children with dysfunctional homografts/ bioprostheses. To date, short and medium follow-up data are encouraging [16].

In a recent animal study, Kiefer et al. examined the effect of Edward SAPIEN valve crimping on valve calcification and durability. Their conclusion was precrimping of the valve for less than 1 day will result in no significant change in the structural integrity of valve tissue compared to the group crimped for more than 1 day. The calcification grade was similar in both groups when compared to a control group [39]. In order to overcome the complications that result from valve calcification and degeneration, ongoing work is being carried out to investigate tissue engineering techniques to preserve valve function [40, 41]. Mid-term follow-up for these tissue-engineered vascular grafts have demonstrated the valves to be safe and effective with excellent hemodynamics in pediatric cardiovascular surgery [42]. Schmidt et al. [43] recently demonstrated that heart valve tissue engineering (HVTE) implantation through the transcatheter approach is feasible but requires technical and financial support. More recently Weber et al. [44] demonstrated successful implantation of bone marrow mononuclear cell (BMMC) derived tissueengineered heart valve (TEHV) into the pulmonary position. In an ovine model,
BMMC-derived TEHV can be implanted successfully using a minimally invasive, onestep, transapical approach in the aortic position [45].

\section{ACKNOWLEDGMENTS}

We gratefully acknowledge Dr. Qi-Ling Cao, for his contribution in the preparation of the images for this article and the staff of the hybrid cardiac catheterization suite at Rush University Medical Center for their hard work and dedication to all of our patients. Dr. Hijazi is the guarantor for this article, and takes responsibility for the integrity of the work as a whole.

Conflict of interest. Dr. Hijazi was a consultant for Edwards Lifesciences, the company that manufactures the Edwards Sapien THV. Drs. Ghawi and Kenny have no conflict of interest related to this study.

Open Access. This article is distributed under the terms of the Creative Commons Attribution Noncommercial License which permits any noncommercial use, distribution, and reproduction in any medium, provided the original author(s) and the source are credited.

\section{REFERENCES}

1. Bove EL, Lupinetti FM, Pridjian AK, et al. Results of a policy of primary repair of truncus arteriosus in the neonate. J Thoracic Cardiovasc Surg. 1993;105: 1057-65.

2. Rastelli GC, Wallace RB, Ongley PA. Complete repair of transposition of the great arteries with pulmonary stenosis. A review and report of a cases corrected by using a new surgical technique. Circulation. 1969;39:83-95.

3. Warnes CA, Williams RB, Bashore TM, et al. ACC/ AHA 2008 Guidelines for the management of adults with congenital heart disease: a report of the 
American College of Cardiology/American Heart Association task force on practice guidelines. Circulation. 2008;118:714-833.

4. Abd El Rahman MY, Abdul-Khaliq H, Vogel M, et al. Relation between right ventricular enlargement, QRS duration, and right ventricular function in patients with tetralogy of Fallot and pulmonary regurgitation after surgical repair. Heart. 2000;84: 416-20.

5. De Ruijter FT, Wernicnk I, Hirchcock FJ, et al. Right ventricular dysfunction and pulmonary valve replacement after correction of tetralogy of Fallot. Ann Thoracic Surg. 2002;73: 1794-800.

6. Therrien J, Siu SC, McLaughlin PR, et al. Pulmonary valve replacement in adults late after repair of tetralogy of Fallot: are we operating too late? J Am Coll Cardiol. 2000;36:1670-5.

7. Batlivala SP, Emani S, Mayer JE, McElhinney DB. Pulmonary valve replacement function in adolescents: a comparison of bioprosthetic valves and homograft conduits. Ann Thorac Surg. 2012;93:2007-16.

8. Carvalho JS, Shinebourne EA, Bussi C, et al. Exercise capacity after complete repair of tetralogy of Fallot: deleterious effects of residual pulmonary regurgitation. Br Heart J. 1992;67: 470-3.

9. Gatzoulis MA, Balaji S, Webber SA, et al. Risk factors for arrhythmia and sudden cardiac death late after repair of tetralogy of Fallot: a multicentre study. Lancet. 2000;356:975-81.

10. Asoh K, Walsh M, Hickey E, et al. Percutaneous pulmonary valve implantation within bioprosthetic valves. Eur Heart J. 2010;31:1404-9.

11. Bonhoeffer $\mathrm{P}$, Boudjemline $\mathrm{Y}$, Zakhia $\mathrm{S}$, et al. Transcatheter implantation of a bovine valve in pulmonary position: a lamb study. Circulation. 2000;102:813-6.

12. Bonhoeffer $\mathrm{P}$, Boudjemline $\mathrm{Y}$, Saliba $\mathrm{Z}$, et al. Percutaneous replacement of pulmonary valve in a right-ventricle to pulmonary-artery prosthetic conduit with valve dysfunction. Lancet. 2000;356: 1403-5.

13. Bonhoeffer P, Boudjemline Y, Qureshi SA, et al. Percutaneous insertion of the pulmonary valve. J Am Coll Cardiol. 2002;39:1664-9.

14. Khambadkone S, Coats L, Tahlor A, et al. Percutaneous pulmonary valve implantation in humans results in 59 consecutive patients. Circulation. 2005;112:1189-97.
15. Lurz P, Coats L, Khambadkone S, et al. Percutaneous pulmonary valve implantation impact of evolving technology and learning curve on clinical outcomes. Circulation. 2008;117:1964-72.

16. McElhinney DB, Hellenbrand WE, Zahn EM, et al. Short- and medium-term outcomes after transcatheter pulmonary valve placement in the expanded multicenter US melody valve trial. Circulation. 2010;122:507-16.

17. Webb JB, Chandavimol M, Thompson $\mathrm{CR}$, et al. Percutaneous aortic valve implantation retrograde from the femoral artery. Circulation. 2006;113: 842-50.

18. Garay F, Webb J, Hijazi ZM. Percutaneous replacement of pulmonary valve using the Edwards-Cribier percutaneous heart valve: first report in a human patient. Catheter Cardiovasc Interv. 2006;67:659-62.

19. Kenny D, Hijazi ZM, Kar S, et al. Percutaneous implantation of the Edwards SAPIEN transcatheter heart valve for conduit failure in the pulmonary position: early phase 1 results from an international multicenter clinical trial. J Am Coll Cardiol. 2011;58:2248-56.

20. US Food and Drug Administration. News and Events: News Room: Press Announcements. Available at: http://www.fda.gov/newsevent/news room/press announcements/ucm198597.htm. Accessed 6 Nov 2011.

21. US Food and Drug administration. News and Events: News Room: Press Announcements. Available at: http://www.fda.gov/NewsEvents/News room/Press Announcements/ucm278348.htm. Accessed 24 Nov 2011.

22. Boone RH, Webb JG, Horlick E, et al. Transcatheter pulmonary valve implantation using the Edwards SAPIEN $^{\mathrm{TM}}$ transcatheter heart valve. Catheter Cardiovasc Interv. 2010;75:286-94.

23. Webb JG, Altwegg L, Masson J, et al. A new transcatheter aortic valve and percutaneous valve delivery system. J Am Coll Cardiol. 2009;53:1855-8.

24. Faza NN, Kenny D, Kavinsky C, Amin Z, Heitschmidt M, Hijazi ZM. Single center comparative outcomes of the Edwards SAPIEN and Medtronic Melody transcatheter heart valves in the pulmonary position. Catheter Cardiovasc Interv. 2012. [Epub ahead of print].

25. Oosterhof T, van Straten A, Vliegen HW, et al. Preoperative thresholds for pulmonary valve replacement in patients with corrected tetralogy of Fallot using cardiovascular magnetic resonance. Circulation. 2007;116:545-51. 
26. Frigiola A, Tsang V, Bull C, et al. Biventricular response after pulmonary valve replacement for right ventricular outflow tract dysfunction: is age a predictor of outcome? Circulation. 2008;118: S182-90.

27. Feltes TF, Bacha E, Beekman RH 3rd, et al. Indications for cardiac catheterization and intervention in pediatric cardiac disease: a scientific statement from the American Heart Association. Circulation. 2011;123:2607-52.

28. Salinger M, Zhao D, Feldman T. Technique of temporary subcutaneous "Figure-of-Eight" sutures to achieve hemostasis after removal of large-caliber femoral venous sheaths. Catheter Cardiovasc Interv. 2011;78:155-60.

29. Sosnowski CR, Kenny D, Hijazi ZM. Bail out use of the gore excluder following pulmonary conduit rupture during transcatheter pulmonary valve replacement. Catheter Cardiovasc Interv. 2012. [Epub ahead of print].

30. Schievano S, Petrini L, Migliavacca F, et al. Finite element analysis of stent deployment: understanding stent fracture in percutaneous pulmonary valve implantation. J Interven Cardiol. 2007;20:546-54.

31. Peng LF, McElhinney DB, Lock JE, et al. Endovascular stenting of obstructed right ventricle-to-pulmonary artery conduits: a 15-year experience. Circulation. 2006;113:2598-605.

32. Nordmeyer J, Khambadkone S, Coats L, et al. Risk stratification, systematic classification, and anticipatory management strategies for stent fracture after percutaneous pulmonary valve implantation. Circulation. 2007;115:1392-7.

33. Demkow M, Biernacka EK, Spiewak $M$, et al. Percutaneous pulmonary valve implantation preceded by routine presenting with a bare metal stent. Catheter Cardiovasc Interv. 2011;77:381-9.

34. McElhinney DB, Cheatham JP, Jones TK, et al. Stent fracture, valve dysfunction, and right ventricular outflow tract reintervention after transcatheter pulmonary valve implantation: patient-related and procedural risk factors in the US Melody Valve Trial. Circ Cardiovasc Interv. 2011;4:602-14.

35. Nordmeyer J, Coats L, Lurz P, et al. Percutaneous pulmonary valve-in-valve implantation: a successful treatment concept for early device failure. Eur Heart J. 2008;29:810-5.

36. Webb JG, Wood DA, Ye J, Gurvitch R, et al. Transcatheter valve-in-valve implantation for failed bioprosthetic heart valves. Circulation. 2010;121:1848-57.

37. Cubeddu RJ, Hijazi ZM. Bailout perventricular pulmonary valve implantation following failed percutaneous attempt using the Edwards Sapien transcatheter heart valve. Catheter Cardiovasc Interv. 2011;77:276-80.

38. Wilson W, Taubert KA, Gewitz M, et al. Prevention of infective endocarditis: guidelines from the American Heart Association. Circulation. 2007;116: 1736-54.

39. Kiefer P, Gruenwald F, Kempfert J, et al. Crimping may affect the durability of transcatheter valves: an experimental analysis. Ann Thorac Surg. 2011;92: 155-60.

40. Dolgin E. Taking tissue engineering to heart. Nat Med. 2011;17:1032-5.

41. Schoen FJ. Evolving concepts of cardiac valve dynamics: the continuum of development, functional structure, pathobiology, and tissue engineering. Circulation. 2008;118:1864-80.

42. Shin'oka T, Matsumura G, Hibino N, et al. Midterm clinical result of tissue-engineered vascular autografts seeded with autologous bone marrow cells. J Thorac Cardiovasc Surg. 2005;129:1330-8.

43. Schmidt D, Dijkman PE, Driessen-Mol A, et al. Minimally-invasive implantation of living tissue engineered heart valves: a comprehensive approach from autologous vascular cells to stem cells. J Am Coll Cardiol. 2010;56:510-20.

44. Weber B, Scherman J, Emmert MY, et al. Injectable living marrow stromal cell-based autologous tissue engineered heart valves: first experiences with a one-step intervention in primates. Eur Heart J. 2011;32:2830-40.

45. Emmert MY, Weber B, Wolint P, et al. Stem cellbased transcatheter aortic valve implantation: first experiences in a pre-clinical model. JACC Cardiovasc Interv. 2012;5:874-83. 